Research Article

\title{
Private Parking Space Sharing Intention in China: An Empirical Study Based on the MIMIC Model
}

\author{
Ange Wang $\mathbb{D}^{1},{ }^{1}$ Hongzhi Guan ${ }^{D},{ }^{1}$ Yan Han, ${ }^{2}$ and Yangliu Cao ${ }^{1}$ \\ ${ }^{1}$ Faculty of Urban Construction, Beijing University of Technology, Beijing 100124, China \\ ${ }^{2}$ Beijing Key Laboratory of Traffic Engineering, Beijing University of Technology, Beijing 100124, China \\ Correspondence should be addressed to Hongzhi Guan; hguan@bjut.edu.cn
}

Received 4 May 2021; Revised 17 June 2021; Accepted 27 June 2021; Published 12 July 2021

Academic Editor: Junhai Ma

Copyright (c) 2021 Ange Wang et al. This is an open access article distributed under the Creative Commons Attribution License, which permits unrestricted use, distribution, and reproduction in any medium, provided the original work is properly cited.

The shared parking scheme improves the utilization rate of existing parking resources and contributes to the sustainable development of cities, but many private parking spaces that are not included in the shared parking scheme have a low utilization rate in China. In order to better promote the shared parking scheme, it is necessary to study the intention of the owners of private parking spaces to share their parking spaces. Therefore, this paper used the Unified Theory of Acceptance and Use of Technology (UTAUT) and Benefit-Risk Analysis Model (BRA) as the combined theoretical framework (C-UTAUT-BRA). Hypothesis testing using the Multiple Indicators and Multiple Causes (MIMIC) model was performed using an empirical assessment of the shared parking scheme in China. The results show that (1) the sharing behavioral intention (BI) is directly affected by perceived benefit (PB), perceived risk (PR), social influence (SI), and facilitating condition (FC) and indirectly affected by effort expectancy (EE), of which the total effect of PB is the largest; (2) exogenous variables have an indirect effect on BI through other psychological latent variables; among them, different sociodemographic and economic characteristics have a significant influence on different latent variables, while the built environment has no significant effect on latent variables. This research contributes to theory building in shared parking participation intention and informs business and government leaders on how to promote the shared parking scheme through the action mechanism of influencing factors on BI.

\section{Introduction}

With the development of society and economy, the number of motor vehicles and the pressure of parking in cities have increased [1-3]. On the one hand, it is due to the insufficient supply of parking spaces. Taking the data of typical first-tier cities in China as an example, the total number of parking spaces is only $64.6 \%$ of the number of vehicles, and by July 2020, China's parking space gap has reached 80 million $[4,5]$. On the other hand, the utilization of parking spaces is not sufficient in certain periods and areas. For example, parking spaces in office areas are usually idle at night and weekends, while private parking spaces in residential areas are often idle during the day on weekdays. According to statistics, 485,000 parking spaces are designated for private use in Hong Kong, accounting for $70 \%$ of the total number of parking spaces; residential parking resources account for
$58.1 \%$ of all parking resources in Beijing, and nearly 800,000 private parking spaces are idle during working hours [6]. That is because most urban residents work inconsistently with their homes, and parking spaces in residential areas have always been idle during working days. If the idle time of private parking spaces in these residential areas can be effectively used, the parking problem can be greatly alleviated. In addition, in the context of sudden public health incidents such as COVID-19, citizens have become more concerned about the hygiene of public transportation and shared bicycles, resulting in a further reduction in the proportion of green travel and an increase in the proportion of private car travel, which aggravates the contradiction between social parking supply and demand.

In recent years, with the development of sharing economy, the concept of shared parking has been put forward. Shared parking schemes allow the owners of private 
parking spaces (individuals or companies) to rent out spaces on the network platform when not in need of them [7]. Travelers with parking needs can purchase parking permits through the online platform. The sharing of private parking spaces can increase the utilization rate of idle parking spaces and bring certain benefits to the sharers. Besides, because the travelers with parking needs have more parking spaces to choose from, it can greatly reduce the time to find parking spaces and further alleviate traffic congestion. In addition, Zhao [8] pointed out that 120 shared parking spaces in Beijing can reduce carbon dioxide emissions by about 400 tons a year; if $20 \%$ of the existing parking spaces in Beijing are shared, carbon dioxide emissions can be reduced by 7.3 million tons per year. Therefore, the shared parking not only can alleviate the parking problem but also can increase the income of suppliers; besides, it can also reduce environmental pollution caused by car emissions.

At present, although some cities have piloted shared parking schemes, people do not know much about shared parking, and people are not willing to supply their own private parking spaces to participate in shared parking, which affects the development of shared parking projects. Therefore, it is necessary to deeply explore the internal and external factors that affect the intention of private parking space owners to supply shared parking spaces, to help platform operators and government departments to introduce corresponding incentive policies.

The rest of this paper is organized as follows: in Section 2, the research hypotheses of this study are proposed after reviewing the literature related to shared parking and research methods; in Section 3, the theoretical applicability and the basic principles of the MIMIC model are introduced; in Section 4, the research survey design, variable measurement, data analysis, and model modification are introduced; in Section 5, the data analysis results of the research model are presented, including the relationship between latent variables and the relationship between latent variables and exogenous variables; in Section 6, the theoretical and practical significance of this study is summarized and the limitations of the current study and the future research directions are also noted.

\section{Literature Review and Research Hypothesis}

2.1. Literature Review. The rise of shared parking has aroused the research interest of scholars. The preliminary research on this topic involves the following three aspects: the selection behavior, matching, and pricing of shared parking.

In terms of the selection behavior of shared parking, Wang et al. [9] constructed structural equation models of cities of different levels in China to explore the factors affecting the intention to participating in shared parking; however, the effect of individual socioeconomic attributes and external factors was not considered. Wang et al. [10] constructed a binary Logistic empirical analysis model of shared parking selection behavior based on the perspective of demanders and analyzed the problems of shared parking in related demonstration units around Hangzhou Bay. Wang et al. [11] constructed a shared parking space selection model for demanders considering the individual's socioeconomic attributes and psychological latent variables. In the related research on the matching of shared parking, Shao et al. [12] established a matching model between residential parking spaces and demanders. Other scholars developed parking matching models based on GIS [13] and cloud technology [14]. Besides, a shared parking dual auction mechanism considering demanders of multiple periods and suppliers of multiple periods of time is also constructed [15]. In addition, Zhao et al. [16] proposed a shared parking resource management framework from both time and space dimensions, considering the uncertainty of the arrival time and departure time of $\mathrm{P}$-users and $\mathrm{O}$-users, and developed an intelligent parking management system (IPMS) to simulate the operation of shared parking. Wang et al. [17] formulated a dynamic optimal supply strategy for parking permits and constructed a stochastic optimal control model to minimize the expected value of the total time loss of the system considering the coexistence of public parking facilities that can be reserved and nonreservable. The charging of shared parking is the most important factor that affects the participation intention of shared parking supply and demand parties. At present, there are many studies on parking pricing, such as parking pricing strategies based on the marginal cost principle and suboptimal pricing theory $[18,19]$ and competitive auction mechanisms based on parking allocation rules and transaction payment rules [15]. In addition, there are related studies on the allocationpricing-revenue mechanism of shared parking and pricing coordination of automobile manufacturers based on government intervention and carbon emission reduction $[20,21]$.

The preliminary research on methodology mainly involves two aspects: the application of the UTAUT model and the BRA model.

In the study of the UTAUT model, Chen et al. [22] used a structural equation model to analyze the quantitative relationship among various influencing factors and built a passenger acceptance model of unmanned buses based on UTAUT. Madigan et al. [23] added hedonic motivation variables based on UTAUT to study passengers' acceptance of automatic road transport systems. Lan et al. [24] introduced price value and other variables to explain the acceptance and use behavior of shared cars. Chen et al. [25] analyzed the impact of "perceived ease of rental and accessibility" and "perceived convenience of travel" on the willingness to use shared bikes from the perspective of product service system. Although the UTAUT model has a strong universality in practice, it cannot fully explain the actual behavior in any case, and there are omissions [26]; that is, in addition to the above factors, the behavioral intention may also be affected by some other hidden factors that have not been discovered. Most of the existing studies incorporate new variables according to the characteristics of the research objects to better explain the intention and behavior of users. In the study of the BRA model, Luo et al. [27] combined the benefit-risk analysis theory and the planned behavior theory to study the effects of perceived 
return, perceived ease of use, perceived usefulness, subjective norms, and perceived behavior control on users' willingness to use Yu'E Bao. Wang et al. [28] combined TAM and BRA theory to study residents' willingness to participate in "Internet + recycling." The extended BRA model enhances the ability to interpret and predict behavioral intentions and behaviors in specific situations.

Although the abovementioned related research is fruitful, there are the following shortcomings: as a prerequisite for the promotion of shared parking, the research on the participation behavior of shared parking is focused on the participation of parking space users (demanders), and in sharing scheme practice, suppliers play an equally important role. Private parking spaces participating in shared parking are essentially private goods, and their supply comes from individuals whose purpose is to obtain a certain income, so their participation in decision-making plays a decisive role in the promotion of shared parking. In addition, there are few studies that combine UTAUT and BRA models to explore behavioral intentions.

In view of the shortcomings of previous studies, this paper combines UTAUT theory and BRA model as the theoretical framework (C-UTAT-BRA) to discuss the effect of psychological latent factors and exogenous factors on the parking space sharing intention of owners, and hypothesis testing using Multiple Indicators and Multiple Causes (MIMIC) model was performed using an empirical assessment of the shared parking schemes in China. The results of this study could provide a reference for the implementation and promotion of the shared parking scheme.

2.2. Research Hypothesis. In this paper, SI refers to the extent to which the sharing intention of the parking space suppliers is influenced by relatives and friends, residents in the same residential area, government, and media; some studies have confirmed that SI is a factor affecting intention to participate [29-31]. EE refers to the expectation of the parking space suppliers on the effort or time that it needs to spend in the process of using the shared parking system to supply parking spaces; FC indicates the degree of influence of external environments such as the ease of use of shared parking system and relevant policy support. Many studies have agreed that EE and FC have a positive impact on BI $[23,32]$.

According to the hypothesis of the UTAUT model on path relationship, users' $\mathrm{BI}$ is directly affected by SI, PE, and $\mathrm{EE}$ and indirectly influenced by FC. Meanwhile, it is affected by the experience, gender, age, and other moderators. However, since shared parking is not widely used, actual behavioral data is difficult to obtain, and BI can well explain actual behavior, so this study uses BI to predict actual behavior $[33,34]$. Therefore, the following hypotheses are proposed:

H1: SI has a positive effect on BI

H2: EE has a positive effect on BI

H3: FC has a positive effect on BI

In this article, PR refers to the potential risks of security, privacy, overtime use of parking spaces, etc., foreseen by the shared parking space suppliers. Hae-Kyung Sohn's [35] research results show that PR can lead to people's negative perception of festivals, and $\mathrm{PB}$ refers to the potential benefits of shared parking space suppliers in terms of rental fee income and social benefits brought by parking spaces sharing. Lee's [36] research results show that the intention to use online banking is mainly negatively affected by security/ privacy risks and financial risks and is mainly positively affected by PB, ATT, and perceived usefulness. Besides, from a psychological point of view, if the shared parking space supplier perceives that the parking sharing behavior brings benefits, it will tend to reproduce the behavior. From an economic point of view, if the benefits of the shared parking space suppliers are higher than the cost of the corresponding behavior, it will prompt them to produce the corresponding intention and behavior. This article puts forward the following hypotheses:

H4: PR has a negative effect on BI

H5: PB has a positive effect on BI

H6: there exists a significant relationship between PB and PR

H7: EE has a positive effect on $\mathrm{PB}$

\section{Methodology}

\subsection{Theoretical Adaptability.}

(1) The Benefit-Risk Analysis (BRA) model takes perceived benefit $(\mathrm{PB})$ and perceived risk (PR) as important variables that affect user's behavioral intention to study human behavior. For the problems proposed in this paper, the behavior of supply shared parking spaces belongs to an individual decision-making process. Besides, participating in shared parking will bring lease income and perceived social benefits to suppliers, such as improving the utilization rate of parking resources and alleviating the problem of social parking difficulties while it also could bring security risks to residential areas. And when users use a parking space over time, it will put the suppliers at risk of not having a parking space available when they return; that is, the psychological game between benefit and risk will affect the intention of parking supply. Therefore, when considering the intention of the participation in the shared parking for parking space owners, it is necessary to consider the potential benefit and potential risk perceived by the supplier to the influence of their sharing intention. Therefore, the BRA model is suitable for this study.

(2) The Unified Theory of Acceptance and Use of Technology (UTAUT) model is a powerful theoretical tool to predict and explain the adoption of information technology by individuals or organizations. It has been widely used in many research fields, such as social behavior, learning behavior, business behavior, and other research fields [37]. 
Venkatesh et al. [38] proposed UTAUT by combining eight theories in different fields, such as the theory of planned behavior, technology task adaptation model, innovation diffusion theory, theory of reasoned action, and social cognition theory. UTAUT proposes four core variables: performance expectancy (PE), effort expectancy (EE), promote condition (PC), social influence (SI), and some controlled variables, such as age and gender. Core variables affect users' intentions, while controlled variables influence behavioral intentions through core variables. The definitions of the core variables are shown in Table 1.

(3) In the practice of shared parking, there are conflicts between suppliers in the distribution of benefits and risks, and as new technology (system) that has not been widely used, the sharing intention of suppliers can be explored with the help of relevant theoretical tools. Therefore, this paper combines with the theoretical framework of the UTAUT mode and BRA mode (C-UTAUT-BRA) to explore the influence of latent variables and exogenous factors on the intention of the owners of private parking spaces. These latent variables such as PE, EE, PC, SI, PR, and $\mathrm{PB}$ and exogenous factors such as sociodemographic and economic characteristics and built environment are listed in Figure 1.

3.2. MIMIC Model. In this paper, the MIMIC model is used to characterize the influence of latent variables and exogenous variables on the private parking space sharing intention.

MIMIC model does not need strict constraint conditions and assumptions to the premise, it can deal with multiple latent variables and endogenous indicators, and it makes exogenous variables and endogenous indicators exist in measurement errors. Therefore, its theoretical framework is more clever than other indirect measure methods and potentially includes other indirect measure methods [39]. Its matrix form is shown in equations (1) and (2):

$$
\begin{aligned}
& \eta=\Gamma x+\zeta, \\
& y=\Lambda \eta+\varepsilon,
\end{aligned}
$$

where $\eta$ is the psychological latent variable vector; $x$ represents the exogenous variable vector; $y$ indicates the observed variable vector; $\Gamma$ and $\Lambda$ are the parameter matrixes; and $\zeta$ and $\varepsilon$ are the measurement errors. Substituting equation (1) into equation (2), we can get equations (3) and (4):

$$
\begin{aligned}
& y=\Lambda(\Gamma x+\zeta)+\varepsilon=\Pi x+\nu \\
& \Pi=\Lambda \Gamma x, \nu=\Lambda \zeta+\varepsilon
\end{aligned}
$$

Assuming that the measurement errors are independent of each other and subject to the normal distribution, then

$$
\begin{aligned}
E\left(\zeta \varepsilon^{\prime}\right) & =0, \\
E\left(\zeta^{2}\right) & =\delta^{2}, \\
E\left(\zeta \varepsilon \varepsilon^{\prime}\right) & =\Theta^{2},
\end{aligned}
$$

where $\Theta^{2}$ is the lower triangular matrix, so the covariance matrix formula is as follows:

$$
\sum(\theta)=E\left(\nu \nu^{\prime}\right)=\delta^{2} \Lambda \Lambda^{\prime}+\Theta^{2} .
$$

The total covariance matrix can be calculated by observing the sample value of the variable; let $\sum=\sum(\theta)$; it can solve each parameter.

In the multi-indicator part of the MIMIC model, it is equivalent to carrying out a confirmatory factor analysis on latent variables. The multicause part can be expressed as follows:

$$
\begin{aligned}
\eta_{l_{i}}= & \gamma_{l_{1}} X_{\mathrm{gen}_{i}}+\gamma_{l_{2}} X_{\text {age }_{i}}+\gamma_{l_{3}} X_{\text {inc }_{i}} \\
& +\gamma_{l_{4}} X_{\text {edu }_{i}}+\gamma_{l_{5}} X_{\text {car }_{i}}+\gamma_{l_{6}} X_{\text {parking }_{i}} \\
& +\gamma_{l_{7}} X_{\text {pub }_{i}}+\gamma_{l_{8}} X_{\text {position }_{i}}+\gamma_{l_{9}} X_{\text {pressure }_{i}} \\
& +\gamma_{l_{10}} X_{\text {inf }_{i}}+\gamma_{l_{11}} X_{\text {city }_{i}}+\gamma_{l_{12}} X_{\text {frequency }_{i}}
\end{aligned}
$$

where $l$ is latent variables, including $\mathrm{EE}, \mathrm{SI}, \mathrm{PC}, \mathrm{PR}, \mathrm{PB}$, and $\mathrm{BI} ; \gamma$ indicates the parameter to be estimated; and $i$ is the observed individual.

The overall structural framework of the berth-sharing intention MIMIC model is shown in Figure 1, including observable exogenous variables (green part), latent variables that constitute C-UTAUT-BRA (blue part), and measurement variables that used to measure latent variables (orange part). The model assumes that exogenous factors such as sociodemographic and economic characteristics and the built environment affect latent variables, and the latent variables of these elements are explained by measured variables. Among them, the structural equation between latent variables and the measurement equation between the latent variables and the measurement variables can reflect the internal influence relationship among the latent variables. The structural equation can reflect whether exogenous variables have an influence on each latent variable and the extent of influence [40].

\section{Survey Design and Data Processing}

4.1. Survey Design. In order to ensure the data quality of the questionnaire, we, respectively, carried out a presurvey and a formal survey. In the presurvey, people with a different understanding of shared parking were asked to fill in the questionnaire, and the formal questionnaire was obtained after adjusting the questionnaire items through the results of presurvey. The formal survey was conducted in the form of an online questionnaire.

The survey mainly aimed at people who have private car spaces in urban areas, and a total of 673 questionnaires were collected. After the conditional screening, the number of valid questionnaires was 625 (the effective rate was 92.3\%). When using the MIMIC model for multivariate studies, the 
TABLE 1: UTAUT core variables and definitions.

$\begin{aligned} & \text { Core } \\ & \text { variable }\end{aligned}$
$\begin{aligned} & \text { The extent to which the individual feels the use of the item is helpful to work } \\ & \text { PE }\end{aligned}$
$\begin{aligned} & \text { The extent to which an individual feels influenced by the group around one person } \\ & \text { FC }\end{aligned}$

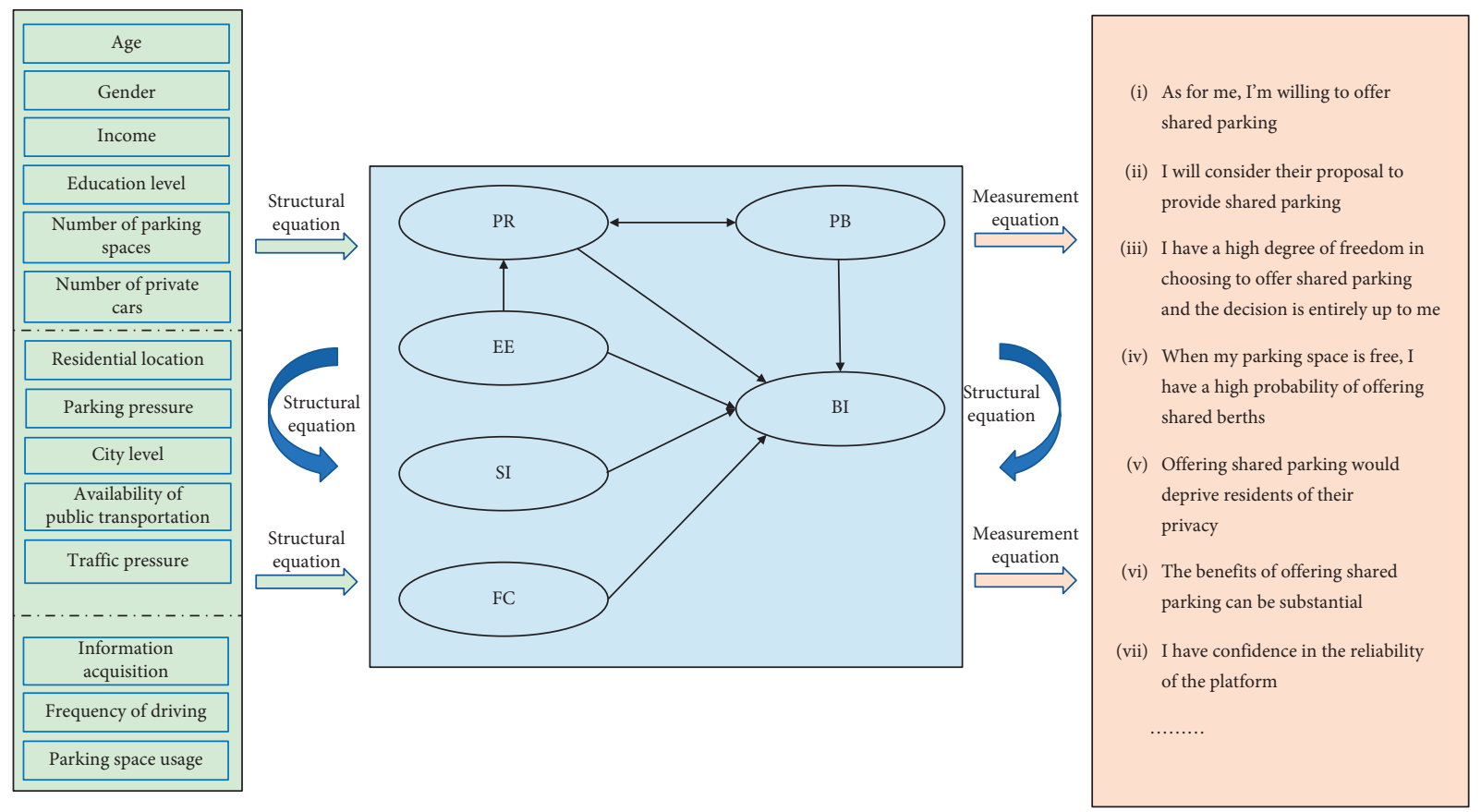

FIGURE 1: Structure framework of the MIMIC model of shared intention.

sample size should be at least 5-10 times the number of variables, so the sample size of the formal survey should be higher than 270. Therefore, the sample size of the formal survey can meet the research needs. The questionnaire's content consists of four parts: the socioeconomic attributes of the informants, the built environment of the surveyed residential area, the usage of parking spaces, and the observed variables of latent variables. Table 2 summarizes the main population characteristics of the effective sample.

This study uses a Likert five-scale ( 1 = strongly disagree; $5=$ completely agree) and measured all psychological variables (C-UTAUT-BRA model variables), and the higher the score, the higher the degree of agreement. According to the research problem, we referred to existing research and interviewed relevant experts to determine the observed variables of the questionnaire. The six latent variables include 27 observed variables; specific observed variables are detailed in Table 3.

4.2. Reliability and Validity Test. Reliability and validity are used to measure the accuracy and stability of questionnaire test results [46]. Reliability analysis is used to measure whether the results of the questionnaire are reliable, and Cronbach's coefficient (Cronbach's $\alpha$ ) is generally used for evaluation. If Kronbach's coefficient is higher than 0.8 , the reliability is high; if it is between 0.7 and 0.8 , the reliability is acceptable; if it is between 0.6 and 0.7 , it is basically acceptable; if it is lower than 0.6 , the reliability is not good and it is necessary to revise the survey scale [47]. Table 4 shows the reliability and validity test results of each latent variable. From the results, Cronbach's coefficient of each latent variable is higher than 0.8 , which indicates that the reliability of the questionnaire is very high.

Validity analysis is used to measure the validity and accuracy of the design of observed variables. The higher the validity, the more accurate the measurement results. Validity is usually verified by using Average Variance Extracted (AVE), and when the value is higher than 0.5 , this indicates that the latent variable has well convergence validity. In addition, when the load coefficient of the standardized factor corresponding to each observed variable is higher than 0.6 and $p<0.05$, it also shows that the convergence validity is up to standard. From the results in Table 4, the AVE of each latent variable is above 0.56 , and the value of each observed variable is above 0.65 , which indicates that the data has strong reliability and internal consistency. 
TABle 2: Description of questionnaire statistics.

\begin{tabular}{|c|c|c|}
\hline Item & Classification & Percentage \\
\hline \multirow{6}{*}{ Age } & $18-25$ & 27.45 \\
\hline & $26-30$ & 13.24 \\
\hline & $31-40$ & 21.57 \\
\hline & $41-50$ & 15.44 \\
\hline & $51-60$ & 17.65 \\
\hline & $>60$ & 1.47 \\
\hline \multirow{2}{*}{ Number of private parking spaces } & 1 & 73.77 \\
\hline & $>1$ & 26.23 \\
\hline \multirow{3}{*}{ Number of private cars } & 1 & 11.27 \\
\hline & 2 & 64.95 \\
\hline & $\geq 3$ & 23.77 \\
\hline \multirow{2}{*}{ Parking space usage } & Irregular & 67.89 \\
\hline & Regular & 32.11 \\
\hline \multirow{4}{*}{ Education level } & High school and below & 31.37 \\
\hline & Junior college/bachelor & 38.48 \\
\hline & Master's degree & 24.51 \\
\hline & Doctorate and above & 5.64 \\
\hline \multirow{5}{*}{ Understanding of shared parking } & Very ignorant & 7.6 \\
\hline & Did not understand & 27.7 \\
\hline & General & 44.36 \\
\hline & To understand & 14.71 \\
\hline & Know very well & 5.64 \\
\hline \multirow{4}{*}{ Frequency of driving (times/day) } & 0 & 17.89 \\
\hline & 1 & 37.99 \\
\hline & 2 & 28.43 \\
\hline & $\geq 3$ & 15.69 \\
\hline \multirow{2}{*}{ Gender } & Male & 58.58 \\
\hline & Female & 41.42 \\
\hline \multirow{5}{*}{ Availability of public transportation } & Very convenient & 7.35 \\
\hline & Less convenient & 8.82 \\
\hline & General & 30.15 \\
\hline & More convenient & 37.25 \\
\hline & Very convenient & 16.42 \\
\hline \multirow{4}{*}{ City level } & First-tier city & 19.36 \\
\hline & Second-tier city & 25.49 \\
\hline & Third-tier city & 25.25 \\
\hline & Fourth-tier city & 29.9 \\
\hline \multirow{6}{*}{ Monthly income (yuan) } & $\leq 3000$ & 25 \\
\hline & $3000-5000$ & 20.83 \\
\hline & $5000-7000$ & 18.14 \\
\hline & $7000-9000$ & 11.27 \\
\hline & $9000-11,000$ & 6.62 \\
\hline & $\geq 11,000$ & 18.14 \\
\hline \multirow{4}{*}{ Location of the community } & Suburb & 13.48 \\
\hline & Suburban area & 19.61 \\
\hline & Away from downtown & 33.58 \\
\hline & Downtown & 33.33 \\
\hline \multirow{3}{*}{ Parking demand of community } & Dissatisfy & 25.49 \\
\hline & Basic satisfy & 52.94 \\
\hline & Satisfy & 21.57 \\
\hline \multirow{5}{*}{ Traffic pressure } & Special congestion & 5.64 \\
\hline & Congestion & 15.93 \\
\hline & General congestion & 47.79 \\
\hline & Comparison of congestion & 8.58 \\
\hline & No congestion & 22.06 \\
\hline
\end{tabular}


TABLE 3: Descriptive statistics of observed variables.

\begin{tabular}{|c|c|c|c|}
\hline $\begin{array}{l}\text { Latent } \\
\text { variable }\end{array}$ & Item & Measurement & Reference \\
\hline \multirow{4}{*}{ PC } & $\mathrm{PC} 1$ & $\begin{array}{c}\text { If the operation of the shared parking system is easy to understand, I would prefer to supply shared } \\
\text { parking spaces }\end{array}$ & \multirow{4}{*}{ [41] } \\
\hline & PC2 & If we establish a shared parking credit mechanism, I would prefer to supply shared parking spaces & \\
\hline & PC3 & $\begin{array}{c}\text { When a parker uses my parking space over time, if the shared parking platform provides me with a spare } \\
\text { parking space, I would prefer to supply a shared parking space }\end{array}$ & \\
\hline & PC4 & $\begin{array}{l}\text { When a parker uses my parking space over time, if the sharing parking platform provides me with } \\
\text { subsidies, I would prefer to supply shared parking space }\end{array}$ & \\
\hline \multirow{5}{*}{ SI } & SI1 & Most people around me will choose to offer shared parking spaces & \multirow{5}{*}[41,42]{} \\
\hline & SI2 & The family will suggest and support me to supply shared parking spaces & \\
\hline & SI3 & riends/classmates/colleagues will suggest and support me to supply shared parking spaces & \\
\hline & SI4 & $\begin{array}{c}\text { Support and appeal from the government and media will let me more willing to supply shared parking } \\
\text { spaces }\end{array}$ & \\
\hline & SI5 & $\begin{array}{l}\text { The more owners who provide shared parking spaces in the community, the more willing I am to supply } \\
\text { shared parking spaces }\end{array}$ & \\
\hline \multirow{4}{*}{$\mathrm{EE}$} & EE1 & Using a shared parking system to supply shared parking spaces is easy & \multirow{4}{*}[32]{} \\
\hline & EE2 & I believe I can supply shared parking spaces through a shared parking system & \\
\hline & EE3 & I have rich knowledge to supply shared parking spaces through the shared parking system & \\
\hline & EE4 & I think I can completely control the use of the shared parking system & \\
\hline \multirow{5}{*}{$\mathrm{PR}$} & PR1 & Parker will park over time, which will cause more inconvenience to me personally & \multirow{5}{*}{ [43] } \\
\hline & PR2 & $\begin{array}{c}\text { Supplying a shared parking space may expose my personal privacy (such as travel records and home } \\
\text { address) }\end{array}$ & \\
\hline & PR3 & Parked car has an accident in the neighborhood; it will probably get me into trouble & \\
\hline & PR4 & Supplying shared parking will increase the cost of new equipment and redevelopment of the parking lot & \\
\hline & PR5 & Supplying shared parking space will increase the pressure of property management in the community & \\
\hline \multirow{5}{*}{$\mathrm{PB}$} & PB1 & Supplying shared parking spaces, I can get a lot of money & \multirow{5}{*}[44]{} \\
\hline & PB2 & Supplying shared parking spaces will improve the utilization rate of idle parking spaces & \\
\hline & PB3 & Supplying shared parking spaces can help solve other people's parking problems & \\
\hline & PB4 & Supplying shared parking spaces will improve the utilization rate of idle parking spaces & \\
\hline & PB5 & Supplying shared parking spaces contributes to the sustainable development of the city & \\
\hline \multirow{4}{*}{ BI } & BI1 & I would like to try to supply shared parking spaces through the shared parking system in the future & \multirow{4}{*}[45]{} \\
\hline & B & $\begin{array}{c}\text { I would like to give priority to supplying shared parking spaces through the shared parking system in the } \\
\text { future }\end{array}$ & \\
\hline & $\mathrm{BI} 3$ & shared parking spaces through the shared parking system in the future & \\
\hline & BI4 & I will strongly recommend to my friends and family to participate in the shared parking program & \\
\hline
\end{tabular}

4.3. Model Modification and Evaluation. This study chose chi-square degree of freedom ratio $\left(\chi^{2} / d f\right)$, Root Mean Squared Error of Approximation (RMSEA), Goodness-ofFit Index (GFI), Comparative Fit Index (CFI), and Adjust Goodness-of-Fit Index (AGFI) as model goodness-of-fit indices. Among them, $\chi^{2} / d f$ is a statistic that directly tests the similarity between the sample covariance matrix and the estimated covariance matrix; the closer $\chi^{2} / d f$ is to 0 , the better the model fits. When the value is lower than 3 , it means that the model fits well; when the value is between 3 and 5, it means that the observed data basically fits the model; when the sample is large, around 5 is acceptable. RMSEA is an absolute index without a baseline model. The smaller its value, the better the model fitness; if the value is lower than 0.05 , this indicates that the model has a good fit, and when the value is 0.08 , it represents the upper limit of the acceptable model fitness [48]. CFI is used to compare the absolute fit of the independent model with the absolute fit of the defined model, and the closer the value is to 1 , the better the result. The closer the value of AGFI is to 1, the higher the model fitness is.
According to the assumption presented, using AMOS established structural equation models to verify the path. The preliminary verification found that the theoretical model and the empirical data could not be completely fitted. Modifying the model without affecting the integrity of the theoretical model, the path that has no significant impact at all is deleted, and the final model fitness test index calculation results are shown in Table 5. The goodness-of-fit indices of the adjusted model all meet the requirements and are obviously better than the initial theoretical model.

\section{Results and Policy Applications}

The optimized MIMIC model is shown in Figure 2. The value on the path in Figure 2 is the standardized path coefficient, which reflects the degree of influence between factors, and the arrow is the influence relationship; $e 1 \sim e 29$ represent the error term. From the calibration results of the MIMIC model, we can see the mutual causality between the latent variables of C-UTAUT-BRA and the relationship between individual exogenous factors and latent variables. 
TABLE 4: Reliability and validity test results.

\begin{tabular}{|c|c|c|c|c|}
\hline \multicolumn{2}{|c|}{$\begin{array}{l}\text { Latent variable } \\
\text { item }\end{array}$} & \multirow{2}{*}{$\begin{array}{c}\text { CFA } \\
0.932\end{array}$} & \multirow[t]{2}{*}{$\alpha$} & \multirow[t]{2}{*}{ AVE } \\
\hline \multirow{4}{*}{ PC } & $\mathrm{PC} 1$ & & & \\
\hline & PC2 & 0.963 & \multirow{3}{*}{0.947} & \multirow{3}{*}{0.811} \\
\hline & PC3 & 0.875 & & \\
\hline & PC4 & 0.826 & & \\
\hline \multirow{4}{*}{ SI } & SI1 & 0.822 & \multirow{4}{*}{0.905} & \multirow{4}{*}{0.744} \\
\hline & SI5 & 0.840 & & \\
\hline & $\mathrm{SI} 3$ & 0.865 & & \\
\hline & SI4 & 0.919 & & \\
\hline \multirow{4}{*}{$\mathrm{EE}$} & EE1 & 0.845 & \multirow{4}{*}{0.935} & \multirow{4}{*}{0.783} \\
\hline & EE2 & 0.938 & & \\
\hline & EE3 & 0.903 & & \\
\hline & EE4 & 0.849 & & \\
\hline \multirow{5}{*}{$\mathrm{PR}$} & PR1 & 0.653 & \multirow{5}{*}{0.861} & \multirow{5}{*}{0.562} \\
\hline & PR2 & 0.806 & & \\
\hline & PR3 & 0.859 & & \\
\hline & PR4 & 0.693 & & \\
\hline & PR5 & 0.718 & & \\
\hline \multirow{5}{*}{$\mathrm{PB}$} & PB1 & 0.671 & \multirow{5}{*}{0.882} & \multirow{5}{*}{0.651} \\
\hline & PB2 & 0.766 & & \\
\hline & PB3 & 0.867 & & \\
\hline & $\mathrm{PB} 4$ & 0.861 & & \\
\hline & PB5 & 0.852 & & \\
\hline \multirow{4}{*}{ BI } & BI1 & 0.936 & \multirow{4}{*}{0.958} & \multirow{4}{*}{0.845} \\
\hline & $\mathrm{BI} 2$ & 0.938 & & \\
\hline & $\mathrm{BI} 3$ & 0.915 & & \\
\hline & BI4 & 0.886 & & \\
\hline
\end{tabular}

TABLE 5: Actual test values and standard values of model fitness indexes.

\begin{tabular}{lccccc}
\hline Indicator & $\chi^{2} / d f$ & RMSEA & GFI & CFI & AGFI \\
\hline TM & 4.542 & 0.120 & 0.711 & 0.841 & 0.652 \\
OM & 2.455 & 0.027 & 0.809 & 0.936 & 0.864 \\
Standard & $<3$ & $<0.3$ & $>0.8$ & $>0.9$ & $>0.8$ \\
\hline
\end{tabular}

TM: theoretical model; OM: optimized model.

5.1. The Relationship between Latent Variables. The path relationship between the latent variables in the MIMIC model is shown in Figure 3. The solid arrow indicates that there is a significant influence relationship, the dashed arrow indicates that there is no significant influence relationship, ${ }^{*}$ means $p<0.05,{ }^{* *}$ means $p<0.01$, and ${ }^{* * *}$ means $p<0.001$.

(1) PB, PR, SI, and FC all have a significant impact on BI at the level of $p<0.05$; in particular, the path coefficient of $\mathrm{PB}$ reaches 0.6, which shows that the parking space sharing intention is largely driven by the expected benefits, so, $\mathrm{H} 1, \mathrm{H} 3, \mathrm{H} 4$, and $\mathrm{H} 5$ are verified. $\mathrm{EE}$ has no direct impact on the $\mathrm{BI}$, but the $\mathrm{PB}$ and $\mathrm{PR}$ indirectly affect $\mathrm{BI}$, so $\mathrm{H} 2$ is not verified. However, EE has a significant impact on $\mathrm{PB}$, which verifies H7. PB has a significant impact on $P R$, but $P R$ has no significant effect on $\mathrm{PB}$, thus partially verifying H6. The hypothesis test results are shown in Table 6.
(2) Not all latent variables have a direct effect on BI. There are direct and indirect effect relationships between latent variables. The direct effect refers to a variable that has a direct effect on another variable without intermediary variables. The indirect effect refers to the indirect effect of a variable on another variable through an intermediary variable. According to the path coefficients between the latent variables, the direct effects, indirect effects, and total effects between the latent variables are obtained. The results are shown in Table 7.

(3) The latent variables that affect $\mathrm{BI}$ in descending order of impact are PB, EE, FC, SI, and PR; among them, $\mathrm{PB}$ has the largest total impact, and PR has the smallest total impact, indicating that, for suppliers, expected benefits are the main driving force for their sharing intention. When the private parking space owner perceives that the shared parking space can obtain better economic benefits and the problem of idle parking space can be solved, the intention of parking space sharing will be stronger, so it is extremely important to enhance the revenue attraction of parking space sharing. However, there are many interested parties involved in shared parking, including operating platforms, properties, and parking space suppliers. It is difficult for shared revenue to meet the expectations of parking suppliers. Although the government is not a profit-making organization, in theory, shared parking can generate more social benefits, such as reducing vacant parking spaces, reducing parking and traffic congestion, and alleviating environmental pollution. Therefore, the government should support financial subsidies to alleviate the cost pressure on suppliers and managers. In addition, shared parking demonstration projects also require government policy and investment support. Demonstration of shared parking projects can increase public awareness of individuals and the public. The perception of potential shared benefits and the implementation effect and social value of shared parking lots should be broadcast to the public. Through demonstration projects, suppliers will be more aware of sharing benefits and risks in practice, thereby eliminating or alleviating their anxiety.

(4) In addition, the impact level of EE is second only to $\mathrm{PB}$, indicating that the better the suppliers' ability to perceive and control the shared parking operation process, the stronger their sharing intention, so related shared parking platforms should pay more attention to related operations. The ease of use of the system focuses on reducing the complexity of using the shared parking operating system and strengthening relevant instructions to promote the sharing intention of parking space owners.

(5) SI positively affects BI, indicating that the sharing intention of parking space owners in residential areas is affected by the opinions of others, government 


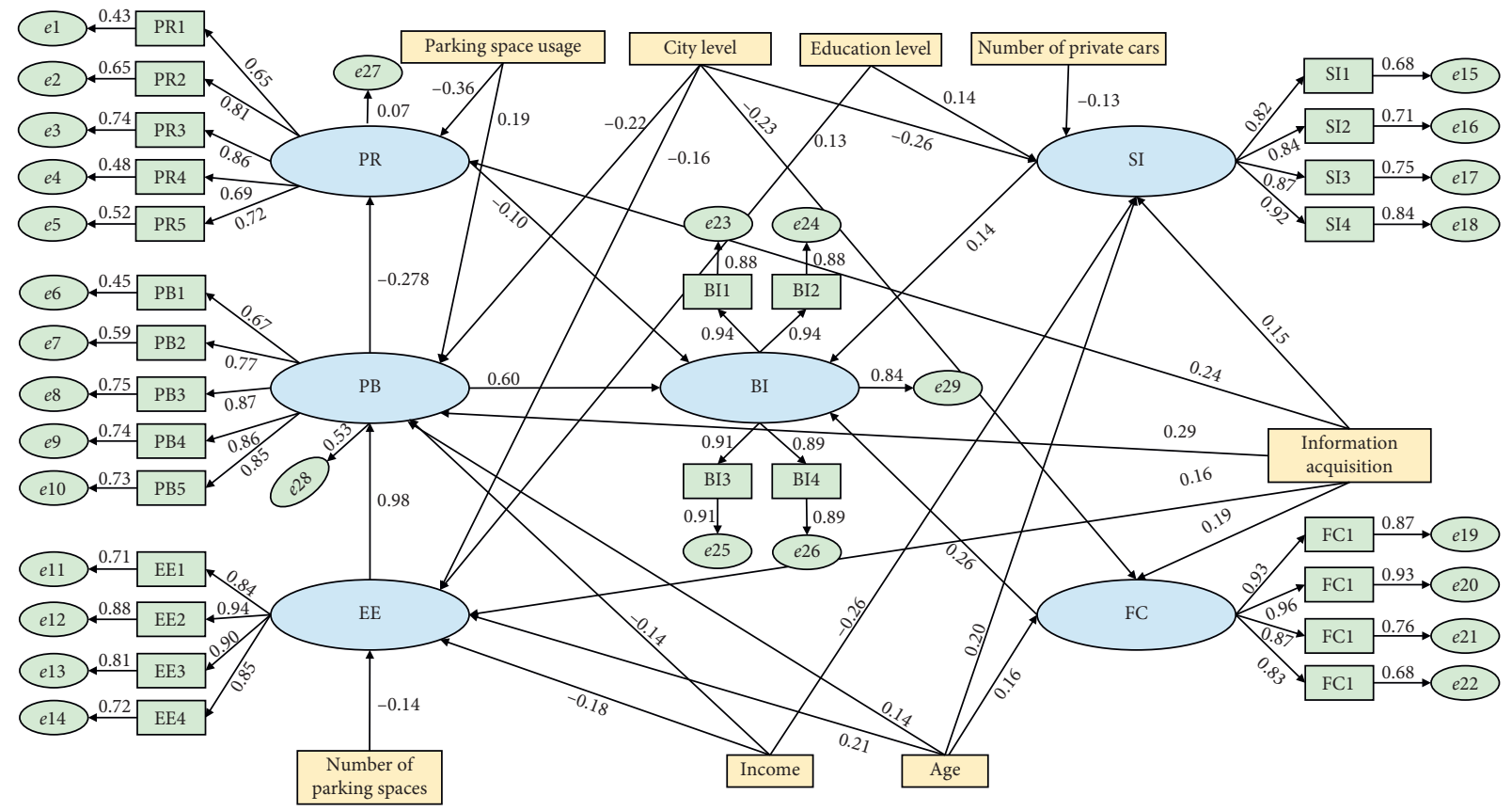

FIGURE 2: MIMIC model of the sharing intention of parking space.

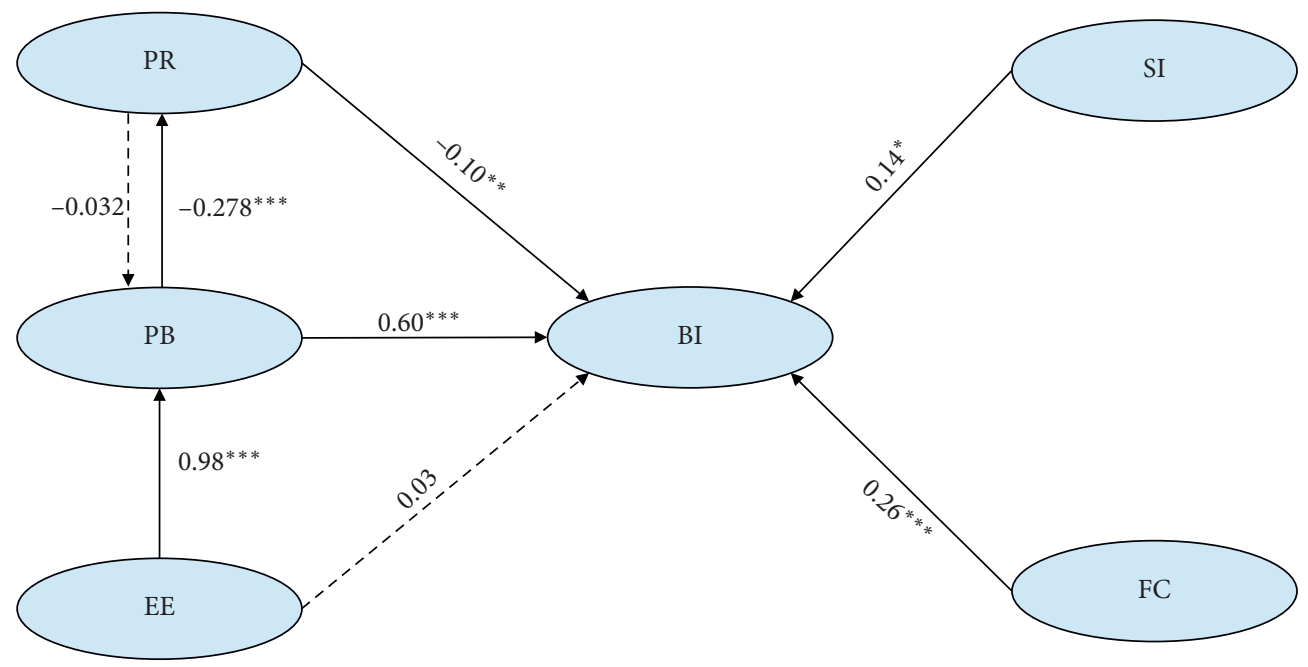

Figure 3: Path relationships between latent variables.

TABLE 6: Test results of the proposed hypotheses.

\begin{tabular}{|c|c|c|c|c|}
\hline Path & Symbol & PC & PV & Inference \\
\hline $\mathrm{H} 1: \mathrm{SI} \longrightarrow \mathrm{BI}$ & + & 0.144 & $* * *$ & Supported \\
\hline $\mathrm{H} 2: \mathrm{EE} \longrightarrow \mathrm{BI}$ & + & 0.027 & 0.686 & Not supported \\
\hline $\mathrm{H} 3: \mathrm{FC} \longrightarrow \mathrm{BI}$ & + & 0.259 & *** & Supported \\
\hline $\mathrm{H} 4: \mathrm{PR} \longrightarrow \mathrm{BI}$ & - & 0.100 & *** & Supported \\
\hline $\mathrm{H} 5: \mathrm{PB} \longrightarrow \mathrm{BI}$ & + & 0.599 & *** & Supported \\
\hline $\mathrm{H} 6: \mathrm{PB} \longrightarrow \mathrm{PR}$ & - & 0.278 & $* * *$ & Supported \\
\hline H6: $\mathrm{PR} \longrightarrow \mathrm{PB}$ & - & 0.032 & 0.570 & Not supported \\
\hline $\mathrm{H} 7: \mathrm{EE} \longrightarrow \mathrm{PB}$ & + & 0.980 & $* * *$ & Supported \\
\hline
\end{tabular}

PC indicates the path coefficient; PV represents the $p$ value ${ }^{* * *} p<0.001$.
TABLE 7: Effect values between latent variables.

\begin{tabular}{lccc}
\hline Path & DEV & IDEV & TEV \\
\hline $\mathrm{PR} \longrightarrow \mathrm{BI}$ & -0.102 & 0.000 & -0.102 \\
$\mathrm{~PB} \longrightarrow \mathrm{BI}$ & 0.601 & -0.028 & 0.572 \\
$\mathrm{SI} \longrightarrow \mathrm{BI}$ & 0.144 & 0.000 & 0.144 \\
$\mathrm{EE} \longrightarrow \mathrm{BI}$ & 0.000 & 0.561 & 0.561 \\
$\mathrm{FC} \longrightarrow \mathrm{BI}$ & 0.259 & 0.000 & 0.259 \\
$\mathrm{EE} \longrightarrow \mathrm{PB}$ & 0.980 & 0.000 & 0.980 \\
$\mathrm{~PB} \longrightarrow \mathrm{PR}$ & -0.278 & 0.000 & -0.278 \\
\hline
\end{tabular}

$\mathrm{DEV}$ indicates the direct effect value; IDEV represents the indirect effect value; TEV is the total effect value. 
TABLE 8: Influence of exogenous factors on latent variables.

\begin{tabular}{|c|c|c|c|c|c|c|c|}
\hline Variable & Gender & Age & $\begin{array}{c}\text { Education } \\
\text { level }\end{array}$ & Income & $\begin{array}{l}\text { Number of } \\
\text { private cars }\end{array}$ & $\begin{array}{c}\text { Number of } \\
\text { parking spaces }\end{array}$ & City level \\
\hline PR & $\begin{array}{c}0.083 \\
(0.758)\end{array}$ & $-0.047(-1.371)$ & $0.069(1.138)$ & $0.000(0.006)$ & $-0.096(-1.174)$ & $0.068(0.795)$ & $0.003(0.055)$ \\
\hline $\mathrm{PB}$ & $\begin{array}{c}0.069 \\
(0.778)\end{array}$ & $0.078^{*}(1.823)$ & $0.012(0.165)$ & $-0.068^{*}(-1.854)$ & $-0.061(-0.060)$ & $-0.150(-1.416)$ & $-0.170^{* *}(-2.874)$ \\
\hline SI & $\begin{array}{c}0.070 \\
(0.572)\end{array}$ & $0.132^{* *}(2.76)$ & $0.158^{*}(1.883)$ & $-0.143^{* * *}(-3.517)$ & $-0.198^{*}(-1.791)$ & $-0.220^{*}(-1.863)$ & $-0.242^{* * *}(-3.662)$ \\
\hline $\mathrm{EE}$ & $\begin{array}{c}0.061 \\
(0.559)\end{array}$ & $0.120^{* *}(2.793)$ & $0.126^{*}(1.672)$ & $-0.085^{*}(-2.289)$ & $-0.031(-0.307)$ & $-0.217^{*}(-2.050)$ & $-0.147^{*}(-2.476)$ \\
\hline FC & $\begin{array}{c}0.162 \\
(1.494)\end{array}$ & $0.089^{*}(2.108)$ & 0.098 (1.315) & $-0.035(-0.969)$ & $-0.124(-1.249)$ & $-0.133(-1.272)$ & $-0.182^{* *}(-3.091)$ \\
\hline
\end{tabular}

Bold font indicates a significant influence relationship. ${ }^{*} \mathrm{p}<0.05 ;{ }^{* *} \mathrm{p}<0.01 ;{ }^{* * *} \mathrm{p}<0.001$.

TABLE 9: Influence of exogenous factors on latent variables.

\begin{tabular}{|c|c|c|c|c|c|c|c|}
\hline Variable & $\begin{array}{l}\text { Residential } \\
\text { location }\end{array}$ & $\begin{array}{l}\text { Parking } \\
\text { pressure }\end{array}$ & $\begin{array}{c}\text { Availability of public } \\
\text { transportation }\end{array}$ & $\begin{array}{c}\text { Traffic } \\
\text { pressure }\end{array}$ & $\begin{array}{l}\text { Frequency of } \\
\text { driving }\end{array}$ & $\begin{array}{c}\text { Parking space } \\
\text { usage }\end{array}$ & $\begin{array}{c}\text { Information } \\
\text { acquisition }\end{array}$ \\
\hline PR & $0.022(0.473)$ & $\begin{array}{l}-0.065 \\
(-0.971)\end{array}$ & $0.042(0.969)$ & $\begin{array}{l}-0.013 \\
(-0.332)\end{array}$ & $0.004(0.086)$ & $0.146^{*}(1.62)$ & $0.162^{* *}(3.268)$ \\
\hline $\mathrm{PB}$ & $-0.072(-1.640)$ & $\begin{array}{l}-0.075 \\
(-0.899)\end{array}$ & $0.031(0.588)$ & $\begin{array}{c}0.021 \\
(0.429)\end{array}$ & $-0.018(-0.312)$ & $0.176^{*}(1.368)$ & $0.267^{* * *}(4.402)$ \\
\hline SI & $0.759(1.354)$ & $\begin{array}{c}0.036 \\
(0.395)\end{array}$ & $-0.037(-0.639)$ & $\begin{array}{c}0.090 \\
(1.614)\end{array}$ & $-0.012(-0.182)$ & $0.058(0.096)$ & $0.166^{*}(0.013)$ \\
\hline $\mathrm{EE}$ & $-0.032(-0.746)$ & $0.02(0.239)$ & $0.055(1.041)$ & $\begin{array}{l}0.047 \\
(0.944)\end{array}$ & $-0.039(-0.675)$ & $0.489(0.351)$ & $0.015^{*}(2.485)$ \\
\hline FC & $-0.071^{*}(-1.865)$ & $\begin{array}{l}-0.016 \\
(-0.198)\end{array}$ & $-0.002(-0.039)$ & $\begin{array}{c}0.064 \\
(1.284)\end{array}$ & $-0.044(-0.759)$ & $0.068(0.876)$ & $0.172^{*}(2.883)$ \\
\hline
\end{tabular}

Bold font indicates a significant influence relationship. ${ }^{*} \mathrm{p}<0.05 ;{ }^{* *} \mathrm{p}<0.01 ;{ }^{* * *} \mathrm{p}<0.001$.

policies, and media propaganda; that is, when making decisions about whether to share parking spaces, they will have a certain degree with reference to the support or encouragement of relatives, friends, colleagues, and the degree of support from the government, so the government can formulate corresponding policies to support the development of shared parking projects and jointly promote the media to increase the public's understanding of shared parking.

(6) The negative impact of PR on BI means that the less risk perceived by the suppliers, the stronger their intention to supply shared parking spaces. If the risks that may exist in the process of parking space sharing are reduced, such as the safety problems caused by the entry of foreign vehicles to the community, the overtime use of parking spaces by users, and the conflicts and disputes caused by the scratching of vehicles during parking, etc., the sharing intention of parking space owners will be promoted.

\subsection{The Relationship between Exogenous Variables and Latent} Variables. The influence of exogenous factors such as socioeconomic characteristics, built environment, and parking space usage on the $\mathrm{PR}, \mathrm{PB}, \mathrm{SI}, \mathrm{EE}$, and FC is summarized in Tables 8 and 9, and $Z$-value is shown in brackets. We can draw the following conclusions:
(1) Exogenous factors do not directly affect BI but indirectly affect BI through PB, PR, SI, FC, and EE.

(2) As can be seen from Table 8, exogenous variables do not have a significant influence on every latent variable; for example, gender has no significant effect on all latent variables; age has a significant positive effect on PB, SI, EE, and FC, indicating that within a certain range, the older the person is, the more sensitive the income of shared parking is, and the greater the expected income is, including personal income and social benefits brought by shared parking. Meanwhile, when the confidence to control the shared parking system is stronger, they more tend to be influenced by society and the people around them. Both education level and income have significant positive effects on SI and EE, indicating that the higher the education level and income, the more willing they are to listen to the opinions of the surrounding groups. Meanwhile, the higher the income, the higher their learning ability and knowledge mastery, and thus the stronger their confidence in the control of the shared parking system. The city level has a negative effect on PB, SI, EE, and FC, indicating that the lower the city level is, the less the perceived revenue is, which may be related to the acceptance of new technology, and the weaker the control confidence is, and it is not easy to be affected by the surrounding environment to participate in 
shared parking. Built environment-related factors of all latent variables were not significant effect, which shows that when making sharing decisions, the owners of private parking spaces pay more attention to the direct benefits brought by shared parking and are less concerned about the potential benefits or risks brought by the surrounding built environment. For example, the convenience of surrounding public transportation may attract more potential users. Besides, the degree of understanding has a significant positive effect on all latent variables.

\section{Conclusions}

The purpose of this study is to explore the influencing factors that affect the parking space sharing intention of owners of private parking spaces in China as well as the relationships between the various factors. A private parking space sharing intention analysis model was constructed by combining the UTAUT model and BRA model. The MIMIC model was applied to describe the measurement relationship between latent variables and measurement variables, latent variables, and exogenous variables, as well as the structural relationships between the latent variables. The data obtained from the actual survey of respondents in China were used to verify the mutual influence relationships in the model quantitatively. In this study, it is found that SI, FC, PB, and PR directly affect $\mathrm{BI}$ and $\mathrm{EE}$ indirectly affect $\mathrm{BI}$ through $\mathrm{PR}$ and $\mathrm{PB}$. The latent variables that affect $\mathrm{BI}$ in descending order of impact are PB, EE, FC, SI, and PR; among them, PB has the largest total impact, and PR has the smallest total impact, indicating that for suppliers, expected benefits are the main driving force for their sharing intention. Relatively speaking, the potential risk of shared parking is not the main factor affecting the sharing intention. Exogenous variables have different effects on different latent variables. Age, education level, and income all have positive effects on SI and EE, while most built-in environmental factors have no significant impact on latent variables, such as the convenience of surrounding public transportation, and traffic pressure. Although the built environment around the shared parking spaces may affect the potential benefits of parking space sharing, the suppliers are not sensitive to this, which may be a factor that shared parking space users are more concerned about. It can be considered that this combined theoretical framework has good applicability for the research of the sharing intention of owners of private parking spaces.

This study has two levels of significance in terms of theoretical enlightenment and practical application reference. At the theoretical level, an empirical basis has been provided for the effective combination of the UTAUT model and BRA, and the theoretical analysis methods have been enriched in the research field of technology acceptance. At the practical application level, this study explored the influencing factors that could affect the parking space sharing intention of owners of private parking spaces in China. An understanding of these factors will be beneficial for analyzing the operating market, thereby providing directions for parking sharing operators and policymakers in future technology research and development as well as functional design. The research results could also provide objective reference opinions for the government to issue management policies for shared parking projects. For example, it is found in this study that PB is the most important influencing factor for sharing intention, so promoters should raise the public's perception of potential shared benefits for individuals and the public.

There are still some limitations in this study: (1) this research only considers the influence of psychological factors and exogenous factors on sharing intention and does not consider the influence of policy variables such as parking charges and overtime charges; (2) this study explores the intention to share parking space rather than actually sharing behavior. In the future, the research can be extended to the investigation of factors affecting sharing behaviors; (3) future research can further explore the influence of participants' behaviors on the stability of the shared parking system and supply behavior analysis under uncertain demand $[49,50]$.

\section{Data Availability}

The data used to support the findings of this study are available from the corresponding author upon request.

\section{Conflicts of Interest}

The authors declare that there are no conflicts of interest regarding the publication of this paper.

\section{Acknowledgments}

This research was funded by the National Natural Science Foundation of China (no. 71971005) and the project sponsored by the Beijing Municipal Natural Science Foundation (no. 8202003). The support is gratefully acknowledged.

\section{References}

[1] R. Arnott and J. Rowse, "Modeling parking," Journal of Urban Economics, vol. 45, no. 1, pp. 97-124, 1999.

[2] D. C. Shoup, "Cruising for parking," Transport Policy, vol. 13, no. 6, pp. 479-486, 2006.

[3] D. Ayala, O. Wolfson, B. Xu et al., "Parking slot assignment games," in Proceedings of the 19th ACM SIGSPATIAL International Conference on Advances in Geographic Information Systems, pp. 299-308, Chicago, IL, USA, November 2011.

[4] Beijing Transportation Development Research Institute, 2020 Annual Report on Beijing Transportation Development, Beijing Research Institute of Transportation Development, Beijing, China, 2020.

[5] Beijing Municipal Commission of Communications, Beijing Parking Resources Survey Report, Beijing Municipal Commission of Communications, Beijing, China, 2017.

[6] Q. Yan, T. Feng, and H. Timmermans, "Investigating private parking space owners' propensity to engage in shared parking schemes under conditions of uncertainty using a hybrid random-parameter logit cumulative prospect theoretic 
model," Transportation Research Part C: Emerging Technologies, vol. 117, Article ID 102776, 2020.

[7] Y. Cai, J. Che, C. Zhang et al., "A parking space allocation method to make a shared parking strategy for appertaining parking lots of public buildings," Sustainability, vol. 11, no. 1, p. 120, 2019.

[8] P. Zhao, H. Guan, P. Wang et al., "Evaluation of environmental benefits caused by reservation-based shared parking: a case study of Beijing, China," IEEE Access, vol. 9, pp. 37443751, 2021.

[9] A. Wang, H. Guan, Y. Han, and Y. Cao, "Study on the intention of private parking space owners of different levels of cities to participate in shared parking in China," Discrete Dynamics in Nature and Society, vol. 2021, Article ID 9955686, 2021.

[10] B. Wang and C. He, "Factors and mechanism of influencing units' staggered sharing berth," Urban Problems, vol. 2019, no. 5, pp. 71-77, 2019.

[11] J. Wang, X. Fu, X. Hu et al., "Analysis of parking choice behavior of residential shared parking space considering psychological latent variables," Journal of Dalian Jiaotong University, vol. 4, pp. 1-5, 2019.

[12] C. Shao, H. Yang, Y. Zhan et al., "A simple reservation and allocation model of shared parking lots," Transportation Research Part C: Emerging Technologies, vol. 71, pp. 303-312, 2016.

[13] M. Iman and A. Hamid, "Applying shared-parking turn-time (SPPC) model and geographic information system in the supply and demand analysis of parking space," Malaysian Journal of Real Estate, vol. 1, no. 2, pp. 57-76, 2006.

[14] O. T. T. Kim, N. D. Tri, N. H. Tran et al., "A shared parking model in vehicular network using fog and cloud environment," in Proceedings of the 2015 17th Asia-Pacific Network Operations and Management Symposium (APNOMS), pp. 321-326, Busan, South Korea, August 2015.

[15] H. Xiao, M. Xu, and Z. Gao, "Shared parking problem: a novel truthful double auction mechanism approach," Transportation Research Part B: Methodological, vol. 109, pp. 40-69, 2018.

[16] P. Zhao, H. Guan, and P. Wang, "Data-driven robust optimal allocation of shared parking spaces strategy considering uncertainty of public users' and owners' arrival and departure: an agent-based approach," IEEE Access, vol. 8, pp. 2418224195, 2020.

[17] P. Wang, A. Wang, H. Guan et al., "Dynamic optimal supply strategy for parking permits," Transportation Systems Engineering and Information, vol. 20, no. 5, pp. 9-14, 2020.

[18] A. Glazer and E. Niskanen, "Parking fees and congestion," Regional Science and Urban Economics, vol. 22, no. 1, pp. 123-132, 1992.

[19] R. G. Lipsey and K. Lancaster, "The general theory of second best," The Review of Economic Studies, vol. 24, no. 1, pp. 11-32, 1956.

[20] P. Wang, H. Guan, P. Liu et al., "Mechanisms of allocation/ pricing/revenue distribution for shared parking lots," China Journal of Highway and Transport, vol. 33, no. 2, pp. 158-169, 2020.

[21] J. Ma, Y. Hou, Z. Wang et al., "Pricing strategy and coordination of automobile manufacturers based on government intervention and carbon emission reduction," Energy Policy, vol. 148, Article ID 111919, 2021.

[22] J. Chen, R. Liu, and Z. Fu, "Passenger acceptance model of unpiloted bus based on UTAUT," Transportation System Engineering and Information, vol. 19, no. 6, pp. 38-44, 2019.
[23] R. Madigan, T. Louw, M. Wilbrink et al., "What influences the decision to use automated public transport? using UTAUT to understand public acceptance of automated road transport systems," Transportation Research Part F: Traffic Psychology and Behavior, vol. 50, pp. 55-64, 2017.

[24] J. Lan and D. Zhu, "Research on the acceptance and use behavior of sustainable transportation consumption: based on the investigation of car sharing in Shanghai," China Population, Resources and Environment, vol. 26, no. 11, pp. 98105, 2016.

[25] C. Chen and X. Li, "Research on the influencing factors of citizens' willingness to use shared bicycles," Journal of Management, vol. 15, no. 11, pp. 1601-1610, 2018.

[26] V. Venkatesh, M. G. Morris, G. B. Davis et al., "User acceptance of information technology: toward a unified view," Management Information Systems Quarterly, vol. 27, no. 3, pp. 425-478, 2003.

[27] C. Luo and X. Zhu, "An empirical study on influencing factors of willingness to use Yu' e bao based on TAM/TPB and perceived risk," Modern Intelligence, vol. 35, no. 2, pp. 143149, 2015.

[28] C. Wang, X. Lv, and Q. Sun, "Research on the influencing factors of residents' willingness to participate in "Internet + recycling"' Journal of Management, vol. 14, no. 12, pp. 1847-1854, 2017.

[29] T. Zhang, D. Tao, X. Qu et al., "Automated vehicle acceptance in China: social influence and initial trust are key determinants," Transportation Research Part C: Emerging Technologies, vol. 112, pp. 220-233, 2020.

[30] I. Panayiotopoulos and G. Dimitrakopoulos, “An empirical investigation on consumers' intentions towards autonomous driving," Transportation Research Part C: Emerging Technologies, vol. 95, pp. 773-784, 2018.

[31] P. Bansal, K. M. Kockelman, and A. Singh, "Assessing public opinions of and interest in new vehicle technologies: an Austin perspective," Transportation Research Part C: Emerging Technologies, vol. 67, pp. 1-14, 2019.

[32] V. Venkatesh, M. G. Morris, G. B. Davis, and F. D. Davis, "User acceptance of information technology: toward a unified view,” MIS Quarterly, vol. 27, no. 3, pp. 425-478, 2003.

[33] R. Chase, Peers Inc: How People and Platforms are Inventing the Collaborative Economy and Reinventing Capitalism, PublicAffairs, New York, NY, USA, 2015.

[34] S. Du, T. Nie, C. Chu et al., "Reciprocal supply chain with intention," European Journal of Operational Research, vol. 239, no. 2, pp. 389-402, 2014.

[35] H. K. Sohn, T. J. Lee, and Y. S. Yoon, "Relationship between PR, evaluation, satisfaction, and behavioral intention: a case of local-festival visitors," Journal of Travel and Tourism Marketing, vol. 33, no. 1, pp. 28-45, 2016.

[36] M. C. Lee, "Factors influencing the adoption of internet banking: an integration of TAM and TPB with PR and PB," Electronic Commerce Research and Applications, vol. 8, no. 3, pp. 130-141, 2009.

[37] D. Zhu, Research on the Influence of Incentive Mechanism on the Parking Behavior of Bike-Sharing Users, Southwest Jiaotong University, Chengdu, China, 2019.

[38] V. Venkatesh, J. Y. L. Thong, and X. Xu, "Consumer acceptance and use of information technology: extending the unified theory of acceptance and use of technology," Management Information Systems Quarterly, vol. 36, no. 1, pp. 157-178, 2012. 
[39] F. Schneider and D. Enste, "Shadow economies around the world-size, causes, and consequences," CESifo Working Paper, 1999.

[40] S. Shu, Y. Bian, J. Rong et al., "A model of intention mimic to transferring car travel to bicycle travel in short distance," Journal of Beijing University of Technology, vol. 45, no. 10, pp. 998-1008, 2019.

[41] R. L. Tompson, C. A. Higgins, and J. M. Howell, "Personal computing: toward a conceptual model of utilization," Management Information Systems Quarterly, vol. 15, no. 1, pp. 125-143, 1991.

[42] I. Ajzen, "The theory of planned behavior," Organizational Behavior and Human Decision Processes, vol. 50, no. 2, pp. 179-211, 1991.

[43] I. Im, Y. Kim, and H. J. Han, "The effects of perceived risk and technology type on users' acceptance of technologies," Information \& Management, vol. 45, no. 1, pp. 1-9, 2008.

[44] M. C. Lee, "Factors influencing the adoption of internet banking: an integration of TAM and TPB with perceived risk and perceived benefit," Electronic Commerce Research and Applications, vol. 8, no. 3, pp. 130-141, 2009.

[45] G. W. H. Tan, K. B. Ooi, L. Y. Leong et al., "Predicting the drivers of behavioral intention to use mobile learning: a hybrid SEM-neural networks approach," Computers in Human Behavior, vol. 36, pp. 198-213, 2014.

[46] N. Golafshani, "Understanding reliability and validity in qualitative research," The Qualitative Report, vol. 8, no. 4, pp. 597-607, 2003.

[47] D. George and P. Mallery, IBM SPSS Statistics 26 Step by Step: A Simple Guide and Reference, Routledge, England, UK, 2019.

[48] R. P. Mcdonald and M. H. R. Ho, "Principles, and practice in reporting structural equation analyses," Psychological Methods, vol. 7, no. 1, p. 64, 2002.

[49] L. Xie, J. Ma and H. Han, Implications of stochastic demand and manufacturers' operational mode on retailer's mixed bundling strategy and its complexity analysis," Applied Mathematical Modelling, vol. 55, pp. 481-501, 2018.

[50] J. Ma and L. Xie, "The comparison and complex analysis on dual-channel supply chain under different channel power structures and uncertain demand," Nonlinear Dynamics, vol. 83, no. 3, pp. 1379-1393, 2016. 